7. Reprod. Fert. (1968) 17, 427-432

\title{
CYCLIC AND PRE-OVULATORY CHANGES IN THE GLYCOGEN CONTENT OF THE FEMALE HAMSTER GENITAL TRACT
}

\author{
A. T. GREGOIRE AND B. J. GUINNESS \\ Department of Obstetrics and Gynecology, University of Michigan Medical Center, and \\ The Center for Research in Reproductive Biology, Ann Arbor, Michigan
}

(Received 11th December 1967, revised 4th March 1968)

\begin{abstract}
Summary. The daily glycogen content of the uterus, cervix, upper and lower vagina and abdominal muscle of the hamster during the 4-day cycle was determined quantitatively by the anthrone method and localized histochemically with the PAS reaction. The amount of glycogen was maximal in the cervical and upper vaginal tissue on Day 1 , the day preceding ovulation. While uterine and vaginal glycogen also increased significantly on Day 1, the increases were not as great as in the other portions of the tract.

A second group of hamsters was killed at $12.00,16.00$ and 20.00 hours on Day 4, 24.00, 12.00, 16.00 and 20.00 hours on Day 1, as well as at 24.00 hours on Day 2. Maximal glycogen levels were demonstrated 9 to $17 \mathrm{hr}$ preceding ovulation at $08.00,12.00$ and 16.00 hours in the cervix and upper vagina. Only slight differences were observed in the uterus and lower vaginal tissue.
\end{abstract}

\section{INTRODUCTION}

Cyclic changes in the uterine glycogen have been described in several species of mammals. In man, endometrium glycogen synthesis and deposition are greatest during the secretory phase (Zondek \& Stein, 1940). The glycogen content of the rat uterus is greatest at pro-oestrus (Boettiger, 1946) and decreases at oestrus. It is localized mainly in the myometrium with the longitudinal muscle layer containing more glycogen than the circular (Bo \& Atkinson, 1952). In the ferret, where ovulation is induced by coital stimulation, the glycogen deposition is maximal at oestrus and is situated mostly in the necks of the endometrial glands (Hamilton \& Gould, 1940).

Investigations of glycogen in the hamster genital tract have been restricted to the pregnant and pseudopregnant animal. The pre-implantation uterine glycogen of the hamster has been reported as small opaque areas at the site of decidualization of pregnant and pseudopregnant animals (Orsini, 1962; Foster, Orsini \& Strong, 1963) and the concentration is greatest at 6 days $12 \mathrm{hr}$ after copulation (Orsini, 1963). 


\section{MATERIALS AND METHODS}

A total of 140 Golden Syrian Hamsters of breeding age and size were used. The vagina was observed daily for cyclic changes (Orsini, 1961) and when the animals had exhibited at least two normal cycles they were killed with ether on a particular day of a subsequent cycle.

Portions of abdominal muscle, uterus, upper two-thirds and lower third of the vagina and the entire cervix were rapidly removed, weighed, placed in $30 \% \mathrm{KOH}$ solution and hydrolysed in a boiling water bath. Glycogen was determined by the anthrone method (Seifter, Dayton, Novic \& Muntwyler, 1950) and expressed as $\mu \mathrm{g} / 100 \mathrm{mg}$ of tissue wet weight. Aliquots of tissue were frozen in a solution of isopentane at $-79^{\circ} \mathrm{C}$, sectioned at $10 \mathrm{~m} \mu$ and stained with periodic acid-Schiff reagent (PAS) for the demonstration of glycogen. A control section was incubated for $1 \mathrm{hr}$ at $37^{\circ} \mathrm{C}$ in a $1 \%$ solution of amylase.

In a second experiment, hamsters were killed at the following times: 12.00, $16.00,20.00$ hours on Day 4; 24.00, 12.00, 16.00, 20.00 hours on Day 1 and 24.00 hours on Day 2. The tissues removed were the same as in the daily studies except that the abdominal muscle was not investigated. The spayed group consisted of ten animals whose ovaries were removed 7 days before slaughter and glycogen determination.

\section{RESULTS AND DISGUSSION}

The amount of glycogen on the days of the cycle and in the several tissues is given in Table 1 and Text-fig. 1 .

The greatest amount of uterine glycogen occurred on the first day of the cycle and decreased significantly $(P<0.05)$ during the remaining days. The PAS method showed that the glycogen is found, as in the rat, in the outer myometrial layer.

The greatest glycogen concentration occurred in cervical tissue and was maximal at Day I $(P<0.01)$, the day preceding ovulation; a rapid decrease followed on subsequent days. The PAS-positive material was restricted to the glandular portion of the cervix, scattered as cytoplasmic granules, while the stromal connective tissue surrounding the lumen was PAS-negative (Pl. 1, Figs. 3 and 4).

The vagina of the hamster consists of two anatomically different sections. The upper two-thirds is composed of convoluted epithelial tissue (Pl. 1, Figs. I and 2) while the lower third consists of stratified squamous epithelium. The greatest amount of glycogen appears in the upper portion of the vagina during

\section{EXPLANATION OF PLATE 1}

FIG. 1. The junction of upper and lower vagina. PAS stain, $\times 100$.

Frg. 2. Upper portion of vagina with deep staining glycogen. PAS stain, $\times 100$.

FIG. 3. Cervical os demonstrating the limitation of glycogen to the glandular area. PAS stain, $\times 100$.

FIG. 4. Cervical glandular tissue with dark staining glycogen deposition. PAS stain, $\times 400$. 
PLATE 1

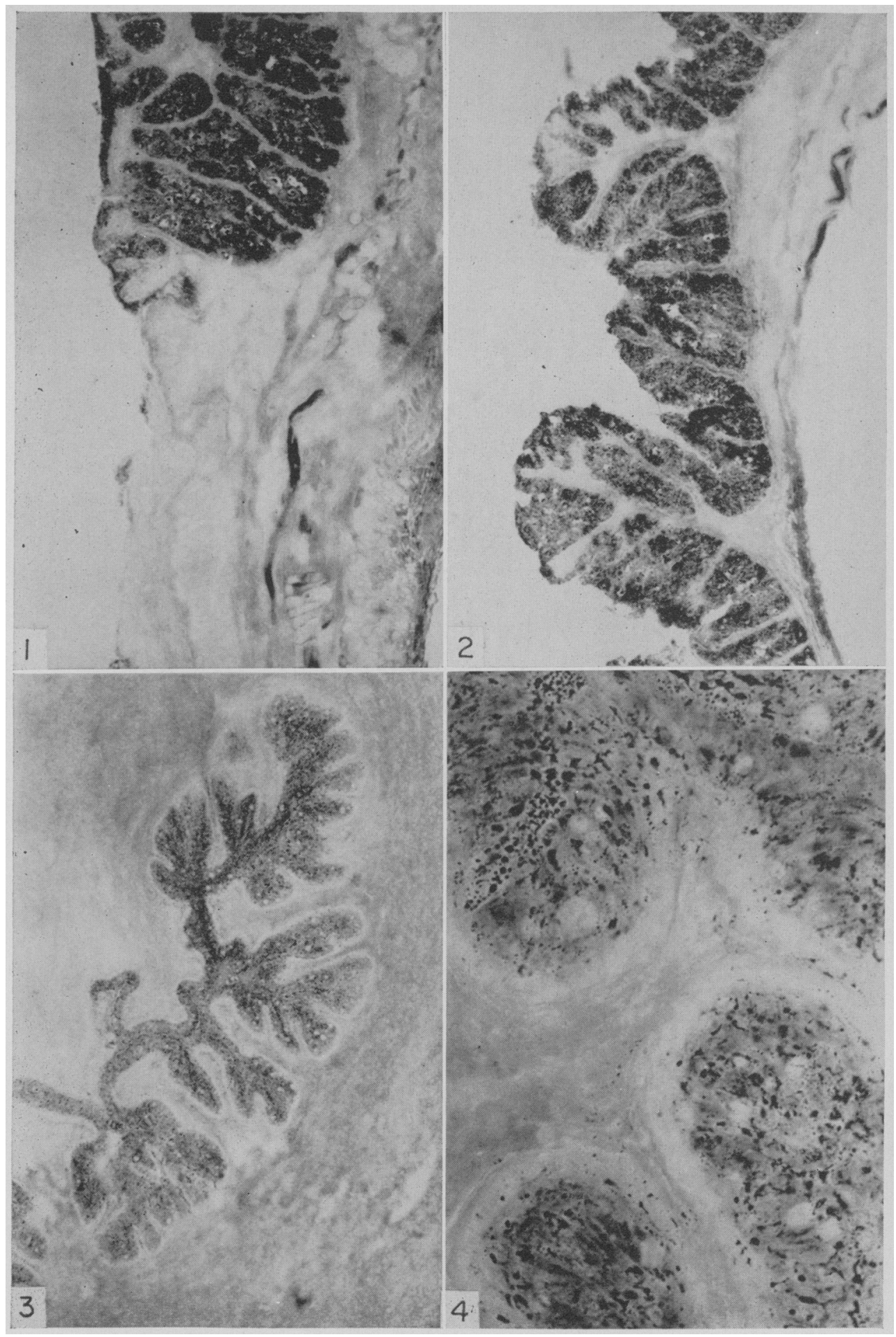

(Facing p. 428) 


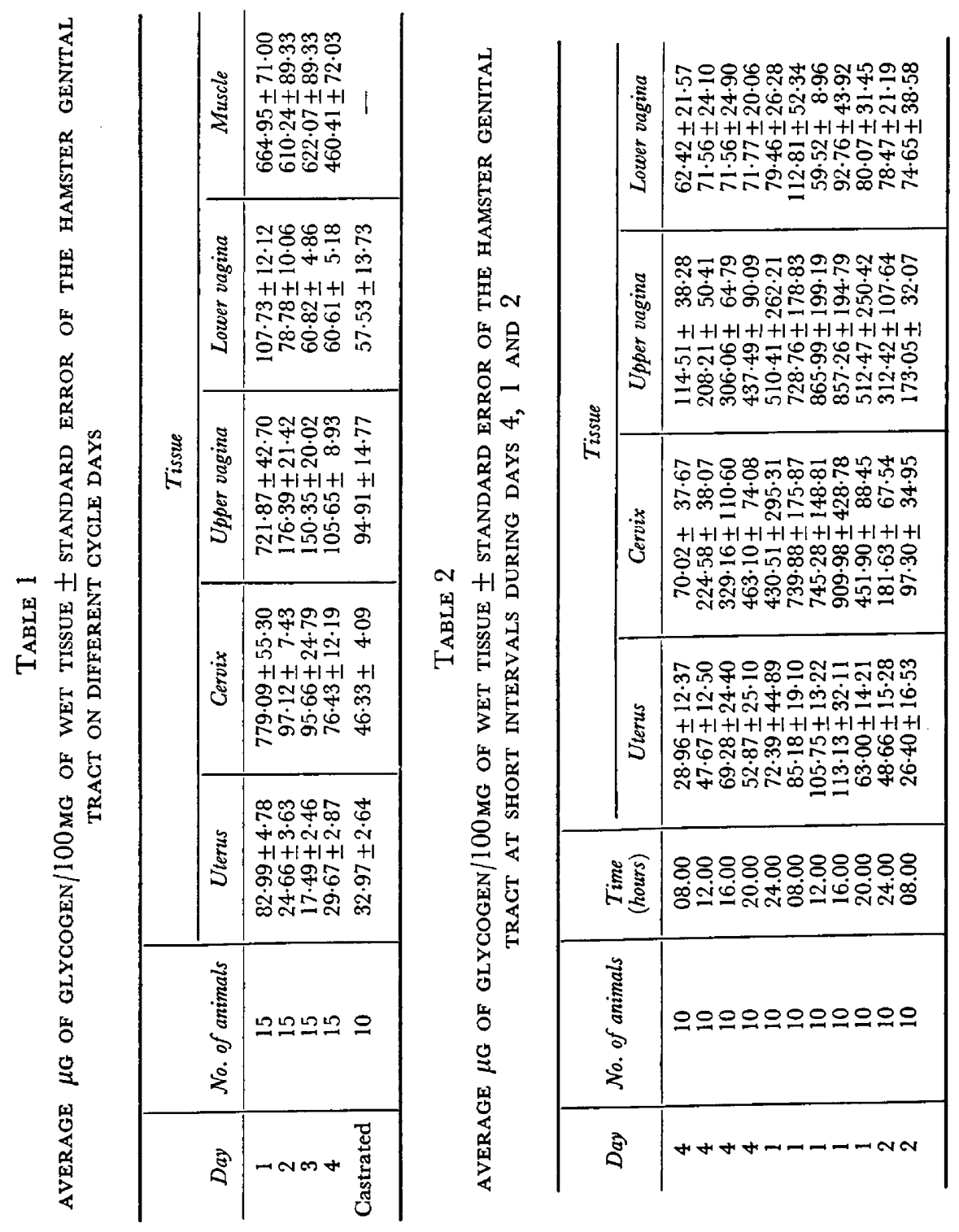




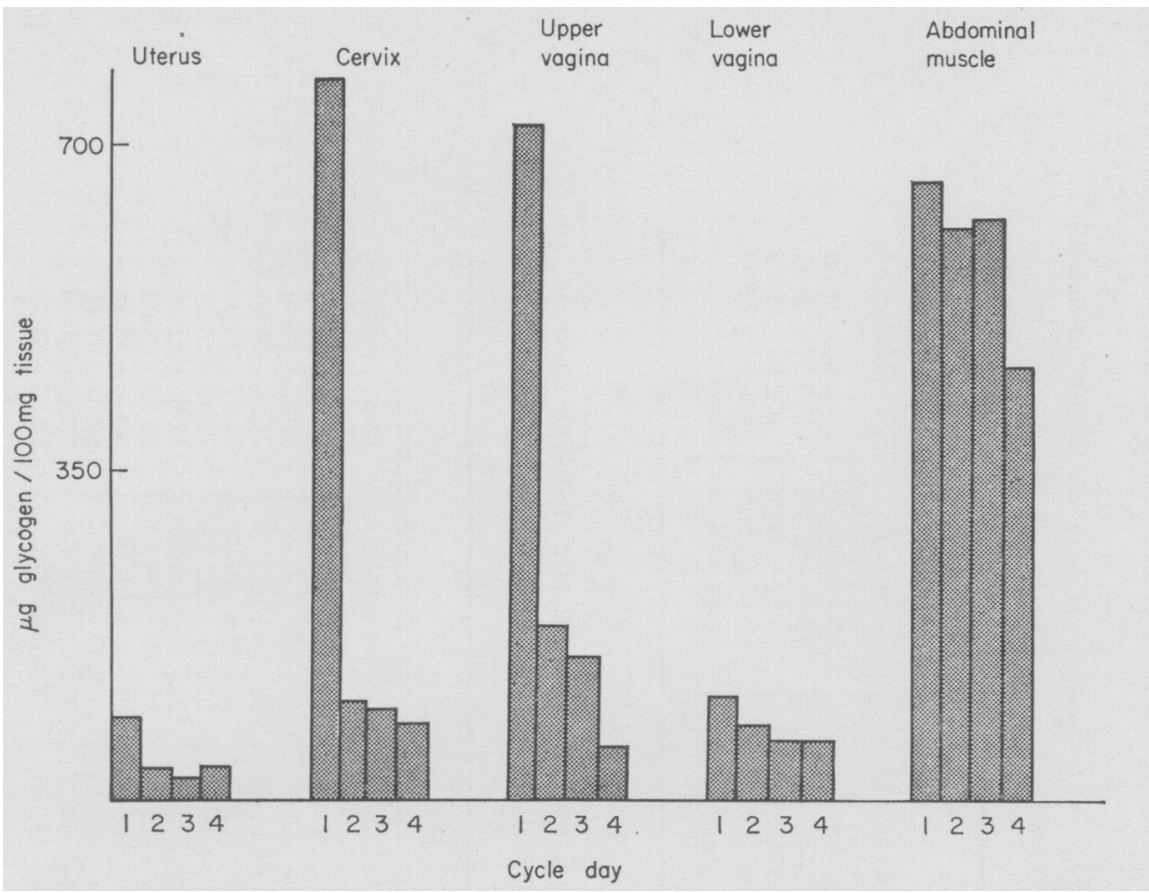

Text-Fig. 1. Average values, $\mu \mathrm{g}$ of glycogen/100 $\mathrm{mg}$ tissue wet weight, of hamster genital tract on different days of the cycle.

the first day $(P<0.01)$ of the cycle, and is present in quantities similar to those in cervical tissue; the lower vaginal tissue contains less glycogen. In the upper vagina the glycogen is restricted to the convoluted epithelial tissue (Pl. 1, Fig. 2); in the lower vagina a slight reaction can be seen in the intermediate and basal layer of the epithelium (Pl. 1, Fig. 1).

Glycogen was more plentiful in abdominal muscle than in the genital tract, except for cervical and vaginal tissue of Day 1 , but did not exhibit significant cyclic changes. Ovariectomy resulted in a decrease in glycogen levels of the entire genital tract.

For the sake of continuity the first ten animals of the daily group, killed at 08.00 hours on Days 4, 1 and 2, are included in Text-fig. 2. In the animals killed at 4-hourly intervals maximal glycogen concentrations were again observed in the cervix and upper vaginal tissues. Only slight pre-ovulatory changes occurred in the uterus and lower portions of the vagina (Table 2).

The maximal glycogen increases in cervical and vaginal tissue occur on Day 1, with the highest levels between 08.00 and 16.00 hours, 9 to $17 \mathrm{hr}$ preceding peak ovulatory activity. In the hamster, oestrus late in the afternoon of Day 1 continues until the early morning of Day 2 and is followed by a post-ovulatory vaginal mucus discharge. During this interval ovulation occurs about 01.00 hours and copulation may occur anytime from late afternoon on Day 1 to early morning of Day 2 (Orsini, 1961). At this time the LH content (Orsini \& Schwartz, 1966) of the pituitary is increased while the amount of 


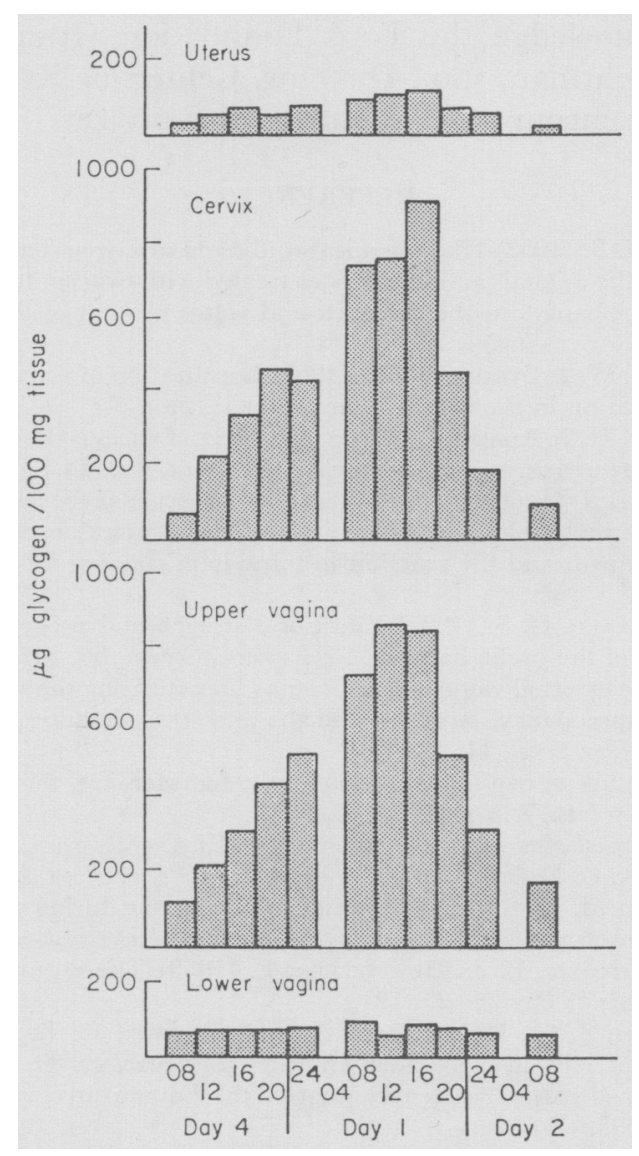

TeXT-FIG. 2. Average glycogen, $\mu \mathrm{g}$ of glycogen $/ 100 \mathrm{mg}$ tissue wet weight, of hamster genital tract at short time intervals during Days 4, 1 and 2 of the 4-day cycle.

FSH is decreased (Keever \& Greenwald, 1967). On Day 1 of the cycle an increase in uterine metabolic activity was observed. The glucose-6-phosphate dehydrogenase activity as well as the proportion of glucose being metabolized by the hexose monophosphate shunt (Warren, Cheatum, Greenwald \& Barker, 1967) is increased.

While the cervix, uterus and vagina are anatomically united, their abilities to synthesize glycogen differ. In the castrated, oestrogen-treated rat, the glycogen values of the cervix are about half that of the uterus and twice that of the vagina (Gregoire, Ramsey \& Adams, 1967). The pre-ovulatory increase in cervical and vaginal glycogen appears to be a result of an enhanced oestrogen secretion by the growing follicle in response to pituitary secretion.

It is possible that the increased cervical and vaginal glycogen have an effect on the ascending spermatozoa, and that either the glycogen itself, or compounds due to enzymatic degradation, are metabolized by the spermatozoa. 


\section{ACKNOWLEDGMENTS}

We gratefully acknowledge the Ford Foundation Grant No. 37482 for its support and S. J. Behrman, M.D., Director, Center for Research in Reproductive Biology, for his encouragement during this project.

\section{REFERENCES}

Bo, W. J. \& Atrinson, W. B. (1952) Histochemical studies on glycogen deposition in the uterus of the rat. I. In intact cyclic animals and in castrates treated with ovarian hormone. Anat. Rec. 113, 91.

Boettiger, E. G. (1946) Changes in the glycogen and water content of the rat uterus. F. cell. comp. Physiol. 27, 9.

Foster, G. A., Orsini, M. W. \& Strong, F. M. (1963) Localization of glycogen in the opacity characterizing decidualization in the cleared hamster uteri. Proc. Soc. exp. Biol. Med. 113, 262.

GregorRe, A. T., Ramsey, H. \& AdAMs, A. (1967) The effect of various doses of oestradiol on glycogen deposition in the rat uterus, cervix and vagina. F. Reprod. Fert. 14, 231.

Hamilton, W. J. \& Gould, J. H. (1940) The normal oestrus cycle of the ferret: The correlation of the vaginal smear and the histology of the genital tract with notes on the distribution of glycogen, the incidence of growth and the reaction to intravitam staining by trypan blue. Trans. $R$. Soc. Edinb. 60, (1) 87.

KeEver, J. E. \& Greenwald, G. S. (1967) Effect of oestrogen and progesterone on pituitary gonadotrophic content of the cyclic hamster. Acta endocr., Copenh. 56, 244.

ORsini, M. W. (1961) The external vaginal phenomena characterizing the stages of the oestrous cycle, pregnancy, pseudopregnancy, lactation and the anoestrous hamster, Mesocricetus auratus Waterhouse. Proc. Anim. Care Panel, 11, 193.

OrsinI, M. W. (1962) Study of ovo-implantation in the hamster, rat, mouse, guinea-pig and rabbit in cleared uterine tracts. F. Reprod. Fert. 3, 288.

Orsin, M. W. (1963) Morphological evidence on the intrauterine career of the ovum. In: Delayed Implantation, pp. 155-169. Ed. A. C. Enders. University of Chicago Press.

Orsin, M. W. \& Schwartz, N. B. (1966) Pituitary LH content during the estrous cycle in female hamsters: Comparison with males and acyclic females. Endocrinology, 78, 34.

Seifter, S., Dayton, S., Novic, B. \& Muntwyler, E. (1950) The estimation of glycogen with the anthrone reagent. Archs Biochem. 25, 191.

Warren, J. G., Cheatum, S. G., Greenwald, G. S. \& Barker, K. L. (1967) Cyclic variation of uterine metabolic activity in the Golden Hamster. Endocrinology, 80, 714.

ZoNDEK, B. \& STEIN, L. (1940) Glycogen content of the human uterine mucosa glycopenia uteri. Endocrinology, 27, 395. 